\title{
Professores de Direito Outróra e hoje
}

João Arruda

\begin{abstract}
"Sob o ponto de vista da cultura, a massa geral franceza é incomparavelmente mais elevada que a brasileira; mas a élite não é nada superior. $\mathrm{Na}$ oratoria e no magisterio, os nossos grandes homens e professores não têm o que invejar aos magnatas da intellectualidade daqui".

(Carta do professor Morato, escripta em Paris, a 15 de Janeiro de 1933).
\end{abstract}

$\mathrm{Na}$ exposição de motivos que precedeu a ultima reforma do ensino juridico, affirmou seu autor, o ministro Francisco de Campos, que nunca tivemos professores de Direito. Não sei por que escola é elle formado para avançar tão inexacta these. Não conhecendo eu a Faculdade de Pernambuco sinão pelos compendios em que estudei Processo Civil, Economia Politica, Direito Ecclesiastico e Direito Civil, sómente direi a impressão que tenho dos grandes mestres da de S. Paulo, que, em tempos passados, illustraram as cathedras donde pontificaram, sendo voz geral que qualquer dos de primeira ordem, como o foram Carrão e Chrispiniano Soares, poderia hombrear com as summidades do magisterio do Velho Continente. Bastam os nomes de Ribas, Chrispiniano, Ramalho, Carrão, Falcão, João Monteiro, Brasilio Machado, João Theodoro, Dutra, Benevides, Duarte de Azevedo, Pedro Lessa e José Bonifacio para o desmentido do asserto do ministro F. de Campos. Quando li a descripção feita por Quesada do modo por que prelecciona Pla- 
Niol, folheando na cathedra rapidamente o Codigo Civil Francez, de que conhece todos os segredos, sem consultar apontamentos, lembrei-me do Dr. João Theodoro ao explicar a Constituição Brasileira argumentando com segurança e celeridade baseado no texto dos varios artigos, folheando o opusculo que tinha nas mãos, e deslumbrando os discipulos por mostrar-se senhor da letra e do espirito da nossa antiga lei basica. Dentre os professores da epocha recente, citarei Almeida Nogueira, Ulpiano, Rafael Correa, José Aranha, Porchat, Gusmão, Estevam de Almeida e Villaboim.

Impossivel é que murchem ao halito do ex-ministro F. de Campos os louros immarcesciveis dos gloriosos mestres que brilharam no velho convento de São Francisco, cujo pobre e humilde aspecto externo era esquecido pelo brilho dos que o frequentavam. O problema que vou affrontar é outro.

Dada a actual e conhecida decadencia do ensino, dado o pouco brilho do magisterio superior de hoje, pergunta-se si se quebraram os moldes em que foram fundidos os gigantes da cathedra cujos nomes acabo de citar. Haverá decadencia da raça, ou surgiu uma sinistra influencia do meio para empanar o brilho da Faculdade?

Presumo que provarei ter sido o factor unico da decadencia do magisterio a diminuição dos venc.mentos e o augmento consideravel o serviço dos professores.

Matriculado estudante em 1877, e tendo entrado para o corpo docente em 1906, estou em condições de fazer o parallelo entre a situação dos professores antigos e a dos actuaes. Mostrarei que os coefficientes de decadencia (augmento de trabalho e diminuição de proventos) foram actuando lentamente desde a reforma Rivadavia, e continuaram grandemente accentuados na F. de Campos.

Quando me refiro á diminuição de vencimentos, não quero dizer que houvesse reduccão da paga aos professores. Isto só aconteceu no ministerio Oswaldo Aranha, quando, em Janeiro de 1931, começou a União a deixar de pagar os 
addicionaes devidos ao magisterio (art. 23 das Disposições Transitorias da Const. de 1934), continuando até este momento a União mensalmente a fazer a suppressão dessa verba dos vencimentos dos professores. Refiro-me porém ao encarecimento da vida, ou depreciação da moéda em que são pagos os funccionarios publicos.

Posta assim a questão, farei o parallelo a que acima alludi.

Em tempos passados, ganhava um professor tanto quanto um desembargador, e era proverbial a expressão “ordenado de desembargador" para significar uma remuneração que deixava o funccionario em condições de não cogitar das suas necessidades economicas na vida, attribuindo-lhe, ao contrario, o que hoje se denomina o standard of life: decente e farta subsistencia. Hoje ganha um desembargador seis vezes o que é dado ao professor, e não é muito. Hoje, segundo calculo meu, que supponho exacto, a vida é nove vezes mais cara do que em 1877.

Passemos ao serviço. $O$ antigo professor dava 4 aulas por semana destinando o sabbado para argumentação entre os alumnos (sabbatina). Estas aulas eram de meia hora, sendo o ultimo quarto, dos tres legaes, destinado á chamada á licção. Na defesa de theses e nos concursos eram os professores dispensados de lêr as monographias que hoje são volumosissimas, e das quaes rarissimas são as proveitosas. São, em geral, com rarissimas excepções, trabalhos feitos com pouco cuidado, obras escriptas ás pressas pelo motivo que desenvolverei em seguida: não haver incentivo para sacrificio da advocacia e de outros trabalhos rendosos ao intento de alcançar uma cathedra na Faculdade. Em vez de lerem essas obras de fancaria, estudavam os antigos professores as theses em autores de nota onde aprendiam bôas doutrinas, e adquiriam sempre novas e proveitosissimas idéas.

A advocacia era rendosissima, embora poucos fossem os pleitos debatidos na tela judiciaria. Para prova, basta re- 
cordar advogados cujo começo de fortuna foi o exercicio da advocacia em São Paulo: Lins, Ferraz, Lessa, Falcão e Carrão.

Tinham os professores sómente de examinar uma vez por anno seus discipulos, cujo numero nunca excedia, sinão rarissimamente, a cincoenta. Fóra a pequena prova escripta de 4 paginas, nada mais tinha o professor a lêr da lavra do alumno.

Pelo que fica exposto, claro se mostra quanto tempo tinha o professor para preparar suas prelecções. Conta Dupin que, neste trabalho de preparo das lições, consumia Cujacio 8 horas. Refere o Dr Alcantara Machado, no perfil que pelas columnas do Jornal do Commercio apresentou de seu saudoso pae Dr Brasilio Machado, o cuidado com que elle preparava suas licções, com as quaes encantava o auditorio: ao talento peregrino juntava o necessario ou indispensavel factor do tempo. para meditação e estudo.

Triste é o quadro hoje. Passa o professor o anno a lêr provas feitas em varias epochas do curso e a ouvir os alumnos em provas parciaes. $O$ intuito do moderno legislador foi introduzir o prof essor na cabeça do alumno a sciencia. Chegou a reforma $\mathrm{F}$. de Campos a referir-se a tempo integral! Seria o melhor processo para encher o quadro do magisterio por vencidos na vida. Desde Dupin, ao explicar como devem ser dadas as lições, até o mais modesto professor de piano ou de dactylographia, todos affirmam uniformemente que o professor não deve passar de um guia do alumno. Dados os conselhos sobre a rota que este deve seguir, cumpre ao discipulo lembrar-se de que sem esforço nada conseguirá. Não conheço pessoalmente o ex-ministro F. de Campos, mas supponho que é homem robustissimo, dotado de invejavel saúde. Só assim se explica que ignore, como ignoram os sadios em relação aos fracos, serem os intellectuaes, quasi sem excepção, homens de pouca saúde, debilissimos. Estas verdades que aqui proclamo foram sempre reconhecidas por todos os mestres, e de recente data é a pergunta de João Mendes sob o regimen Rivadavia, ao vêr deante de si na 
Secretaria as provas escriptas dos alumnos: "Que peccado commetti para ter de fazer este enfadonho e inutilissimo serviço de lêr todas estas provas? "Que diria o grande mestre no regimen $\mathrm{F}$. de Campos?

Os concursos são interminaveis, mórmente tendo os directores, quando não exercitam a advocacia, o habito de os reunir em uma só epocha. Em um desses trabalhos, difficil foi levar a termo a prova, porque quasi todos os professores adoeceram! Occorreu ainda que, tendo um collega do fôro tido noticia de que eu estava prisioneiro na Faculdade, com aquella confraternidade ás vessas que reina no fôro, clandestinamente (e nada mais clandestino que uma audiencia), abriu uma dilação probatoria em certo processo em que eu era o unico advogado de um dos litigantes... Durante esse mez de concurso, desgostavam-se os clientes por não verem apparecer no escriptorio o seu advogado. Sendo o magisterio um importante motivo para perder o advogado a clientela, é evidente que os astros de primeira grandeza no fôro, que muito bem sabem disto, só buscarão o logar de professor ou de docente livre com um minimo de sacrificio, e unicamente para recommendação do seu escriptorio. Não poderão pensar em fazer serviço que lhes tome o tempo indispensavel para bom desempenho do seu ministerio forense, seguros de que o publico é inexoravel para com os profissionaes que não dedicam todos os seus esforços em pról de seus constituintes. Pelo que acabo de referir, conclue-se não ser muito seductora a profissão de mestre em escolas superiores. Ainda mesmo para recommendação do escriptorio, é fraquissimo elemento de prosperidade ser professor de Direito, visto como não podem esses funccionarios dar ao fôro a attenção que elle exige, e, além disto, não significa hoje seja o advogado mestre de Direito um homem de rara cultura, porque não passa de um infeliz condemnado a lêr provas escriptas de seus discipulos durante grande parte do anno.

Esta observação arrasta-me ao exame do aspecto moral, deixando o economico: continuarão os professores a merecer o respeito, a consideração de que eram rodeados outro- 
ra? Ninguem ignora no fôro que Chrispiniano ao subir á tribuna para defender certo cliente, disse que sua presença era a prova mais eloquente da importancia do pleito. Inesquecivel é a phrase de Falcão Filho, quando certo estudante se metteu a critico das doutrhas da cadeira: "Quem é o senhor para, do alto dos seus tamancos, ousar criticar-me?"

Grande factor da pouca importancia do titulo de professor é o augmento do numero delles pela instituição das Faculdades livres, contra as quaes, seja desde já dicto, como explicarei linhas abaixo, nenhuma antipathia nutro, uma vez que entrem no regimen da fiscalização real, fiscalização que attingiria seu maximo pela officialização dos exames.

Reatando porém o fio de minha exposição sobre o pouco valor hoje ligado ao professor, insistirei em que me parece erro grave obrigar os professores a trabalhos acima de suas forças, partindo da presumpção de que têm a saúde de carroceiros vigorosissimos, e perdendo elles, por esse negimen, sua capacidade para outros trabalhos proveitosissimos á instrucção dos alumnos e mesmo ao esclarecimento do governo do paiz. Todos devemos ter presente aquella verdade proclamada por Oxenstrenn: "Nescis, fili mi, quantilla prudentia homines regantur", bem como o asserto de que "Adam. Smith fez mais pelas fianças da Inglaterra do que todos os ministros do Reino", Já em outro escripto meu, fiz sentir que, quando o Governo consulta a Congregação dos professores, é para fazer justamente o contrario do que ella decidiu. Não escapa a esta regra o ex-ministro $F$. de Campos. Victoriosa a revolução de 1930 , determinou o ministro que eu, no exercicio da directoria, convocasse a congregação para ésta expôr-lhe idéas sobre a reforma do ensino. Fiz-lhe sentir a difficuldade de levar a termo tal empreza, estando a Faculdade em férias. Consegui porém, felizmente, o que desejava o ministro, e enviei-lhe relatorio circumstanciado do que indicavam os meus collegas. Algumas semanas depois, surgia pela imprensa noticia de que ia ser feita a reforma por outros moldes, e é a ultima, a de 1931, que é contraria a tudo quanto indicou a congregação, 
e que me parece haver dado, como previam os mestres, péssimos resultados.

Tornando porém ao ponto capital deste artigo, direi que é de inferir-se, pelo que fica dicto sobre a absorpção do tempo do professor, miseravelmente pago, dedicar elle o menor esforço no desenvolvimento de seus estudos academicos, cu destinados á cultura dos estudantes. E' mesmo de temer que voltem alguns ao antigo systema dos primitivos lentes menos zelosos de seu nome e de seus deveres, de lerem uma caderneta mantida sempre a mesma para dsempenho do cargo, sendo de tradição que uma dellas nem fôra escripta pelo titular da cadeira, e sim por um collega desejoso de acudir á pouca intelligencia do infeliz cathedratico: não nego que, ao lado de Carrão, Ramalho e Chrispiniano, havia homens de baixa estatura.

Na Revista do Direito Internacional, (T. XII, pag. 581 e segs.), fundada e dirigida pelo conhecido professor La Pradelle, encontrei um artigo de John B. Whitton, professor de Princetown, em que são desenvolvidas as idéas que estou a prégar neste. Diz o mestre relativamente ao ensino em seu paiz, a America do Norte: "Considerando este assumpto (investigações do professor a bem do progresso scientifico e para a busca da verdade) por um prisma mais restricto, nós encontramos outros obstaculos. Dentre os mais competentes de nossos sabios, muitos têm de tal modo occupações no magisterio que pouco tempo lhes resta para suas proprias investigações. As universidades que esmagam seus homens capazes de investigações sob o peso do horario absorvente, commettem uma espoliação contra a sociedade privando-a das descobertas que poderiam fazer os que estão em condições de seguir seus mais altos interesses" Cita Whitton ainda a opinião de OGG: "O professor acurvado sob o peso de um emprego de tempo muitissimo fatigante, como ficou provado em recentes estudos, raramente tem coragem, energia e meios de proseguir em qualquer estudo proprio. Em geral as investigações florecem numa atmos- 
phera que deixa tempo, para exame tranquillo e reflectido de elementos assim socegadamente colligidos"

Não se esqueçam os que gostarem de acoimar-me de anarchista de que as investigações sobre o cansaço ou esgotamento das forças intellectuaes de que dei rapida noticia em minha prelecção inaugural publicada na Rev. da Fac. Vol. 27 pags. 163 e segs. são hoje universalmente havidas por verdadeiras.

Quaes porém as reformas que indico? Ao expol-as, quero accentuar nada de novo lembrar eu, mas sim applicar ao curso superior o que houve em outros cursos, notadamente quanto aos denominados exames de preparatorios ou estudos propedeuticos, e mesmo á nossa Faculdade. Esta cautela é boa, porque, tendo, ha alguns annos, proposto a Faculdade de São Paulo, por iniciativa minha, certos melhoramentos no ensino, um lente de Pernambuco acoimou-me de autor de idéas subversivas do approvado pela tradição. Ao contrario do que affirmou o meu collega extremamente direitista, eu nunca fui dos que se denominavam partidarios de especulações, e mais tarde utopistas, e emfim apostolos da systematização, isto é, individuos que imaginam uma nova constituição social. Sempre fui do numero dos que desejam reformas parciaes, embora mais ou menos vastas, e mais ou menos constantes: sou reformista. Desejo retoques em varios pontos do que está constituido, e nunca transformação radical da legislação: inclino-me á politica experimental.

Antes de tudo, desejo que se acabe esta mania de matar o funccionario com trabalho inutil. Noticiava a imprensa, faz poucos annos, que um interventor do Norte publicára uma circular, manifesto ou coisa semelhante, dizendo que "quem recebe dinheiro do governo deve trabalhar até morrer de fadiga, ou deixar o emprego" Não é só idéa do homem do Norte. Aqui, em São Paulo, em plena Capital, ha um chefe de repartição que obriga os dactylographos a tiranem multiplas cópias de um mesmo officio, prohibindolhes o emprego do apparelho multiplicador que possue o 
governo para este effeito!. Faz lembrar o juiz que sentia não poder dar sentença contra ambos os litigantes: é uma modalidade do sadismo. Torne o professor a ser guia, e não preparador de infusões scientificas para serem injectadas no alumno, eis o que peço.

Não sou contrario ás Faculdades livres, uma vez que tenho visto bachareis por ellas formados perfeitamente preparados, e a rivalizarem com os das Faculdades officiaes. Como porém é necessario que o Estado garanta ao publico um minimo de preparo nos profissionaes que se dedicam á advocacia, sendo pelo menos ésta a idéa victoriosa em nossa sociedade, como se mostra pela instituição da Ordem dos Advogados, julgo que o Governo deve promover uma fiscalização muito mais rigorosa do que a hoje feita nos exames dos candidatos ao exercicio da advocacia. Os examinadores devem ser pessôas de nomeação e inteira confiança official. Podem ser os professores das faculdades officiaes, ou commissões, nos varios Estados, de nomeação do Governo, do Ministerio da Instrucção Publica. Isto quanto á concessão do titulo de advogado. Entendo porém que o ensino exclusivamente official é damnoso, podendo levar a conformar-se o corpo discente com idéas antiquadas de professores que não acompanharam o movimento de progresso da sciencia. Será inconveniente permittir o ensino livre em se tratando de Medicina ou Engenharia. São ramos scientificos que dependem, para regular estudo, de gabinetes de experiencias, ou de hospitaes de que não dispõem todos os recantos do Brasil. Direito porém restuda-se unicamente com livros, e estes podem ser facilmente adquiridos mesmo nos mais remotos sertões do Brasil, desenvolvido como se acha o serviço postal. Nem ha necessidade de instituição de faculdades livres: qualquer docente particular pode instruir rapazes para exames brilhantissimos perante as commissões officiaes. Si é certo que o Direito Administrativo, a Sciencia das Finanças, o Direito Penal e outras disciplinas exigem do docente conhecimentos dos progressos scientificos, é tambem fóra de duvida que o estudo do Direito Romano, necessario 
para bôa comprehensão do Direito Civil Patrio, só requer dois livros, como disse um saudoso professor de Direito Civil: o de Bonjean e o Corpus Juris. Eu diria que ha um outro livro tão completo quanto o de Bonjean: é o de OrTOLAN. Formuladas programmas de exames pelas commissões. officiaes, como o são, para os concursos, os pontos apresentados aos candidatos pelas congregações, facil será apurar si a estudante tem este minimo indispensavel para exercer a advocacia sem pôr em perigo interesses respeitaveis, e que devem ser acautelados pelo Estado. Outro assumpto importantissimo e digno de estudo é o do comparecimento obrigatorio dos alumnos ás aulas. No tempo em que o professor podia forçar o discipulo a prestar attenção ás suas lições, era comprehensivel obrigal-os ao comparecimento a umas. tantas aulas. Hoje porém, quando o alumno vadio põe-se a lêr um jornal no banco da frente, pinturescamente denominado banco da musica, ou fica a jogar nos bancos mais afastados da cathedra, inefficaz é a medida. Em minhas aulas evitei, quanto possivel, o rigor nesta medida que tem o gravissimo inconveniente de impedir os estudiosos de prestar a attenção que desejam dar ao professor: o vadio fica a conversar em voz, mais ou menos alta, pertubando mestres e collegas. Si o professor ensina bem, é claro que terá sempre auditorio.

Seja-me permittido um exemplo. Ao tempo do chamado ensino livre, em 1881, quando eu cursava o $5 .^{\circ}$ anno, a aula mais frequentada era a do C.० Ramalho: fechavam os. estudantes as portas, para não perderem nem uma só palavra da fraca voz do grande mestre. Os vadios lá não appareciam para incommodar os estudiosos. Com a marcaçãode faltas, a aula do não menos illustre professor João Mendes era perturbadissima pelos alumnos pouco amigos do estudo, sendo isto extranhavel quando era certo, que além. da admiração votada pelo corpo discente ao notavel jurista, ainda se dava a circumstancia da grande estima em que era tido por todos: professores e alumnos. Entendo pois que 
a obrigatoriedade de comparecimento é de effeito contrario ao que tinha o legislador em mente.

Não supponho que o professor seja dispensavel para o ensino do Direito e mesmo de qualquer outra disciplina, mas creio que razão tem HuxLEY quando affirma que muito mais do que o mestre, e em complemento dos conselhos dados: por tão importante guia, ha o livro. Do mestre não se pode dizer o que disse Victor Hugo dos monumentos: "Ceci tuera cela" Nunca será o mestre substituido pelo livro. O livro porém será sempre o auxiliar importantissimo do mestre, particularmente para aperfeiçoar-se o discipulo.

Não ha duvida sobre a decadencia dos estudos, como se revela até nos concursos. Candidato que não poude terminar a prelecção foi caso virgem nos annaes academicos, e occorreu faz poucos mezes. Mas o que vae assombrar o leitor é affirmar eu que os candidatos que assim deram prova de falta de conhecimentos èram moços intelligentissimos e de cultura não vulgar, o que posso affirmar com segurança por terem sido meus discipulos no curso do doutorado. Como pois explicar o facto? Elle é a confirmação do que acima disse eu: pouco zelo no preparo para o concurso. Esses candidatos não quizeram sacrificar os serviços importantes e remuneradores por estudos para um certamen que lhes daria, quando muito, um titulo hoje tão pouco importante de professor.

Cotejem-se os trabalhos apresentados á Faculdade com os memoriaes (trabalhos forenses impressos), e ver-se-á que estes provam estudos carinhosamente feitos de pontos de Direito, revelando nos autores cultura não vulgar e san doutrina. Si algum trabalho é apresentado aos tribunaes judiciarios por profissional que pouca doutrina mostra, logo recebe a critica dos collegas, donde a conclusão que ha quem entenda da theoria juridica. Um exemplo tornará mais claro o que digo. Certo advogado publicou umas allegações em que começava o trabalho defendendo, na interpretação. de um texto de lei, a doutrina de Laurent, Bugnet e outros. 
antigos mestres de Hermeneutica, e acabava com as de GÉNY, Vander Eycken, Kantorowicz e de outros innovadores. Pois bem! Uns dez ou doze collegas fizeram-me ver, criticando o opusculo, que o advogado defendera opiniões que "hurlent de se trouver ensemble".

Levantar o nivel da instrucção é o escopo de todos. Por este motivo escrevo estas poucas linhas, e temeroso de que haja alguem que me accuse de ser anarchista, direi que o plano por mim indicado foi o seguido sempre em relação aos exames de preparatorios em nosso paiz. Póde não convir para os estudos de Medicina, e Engenharia, seja repetido, mas nenhuma desvantagem ha em sua adopção para o preparo em Direito.

Quereria, por acaso, o ministro $F$ dE CAMPos dizer que os grandes jurisconsultos a que acima fiz referencia sabiam Direito, mas não sabiam ensinar? Contra ésta these se acha o facto de terem sido seus discipulos Ruy Barbosa, LAFAyetTe, Bernardo Pereira de Vasconcellos, Candido Mendes, Visconde de Ouro Preto, Conde de Affonso Celso, Marquez de Sáo Vicente, M. I. Carvalho de Mendonça, J X. Carvalyo DE Mendoça e muitos outros notaveis juristas.

Não ha decadencia da raça como querem certos intitulados sociologos e anthropologos, não ha influencia deleteria do athletismo como querem outros que se presumem sabios em assumptos sociaes, mas ha má organização do ensino, péssima retribuição do magisterio. Contra ésta opinião dos nossos sabios, basta citar a Grecia antiga onde em tanta estima foram tidos os jogos destinados ao desenvolvimento physico. Embora reformista, julgo que profundas alterações devem ser feitas no ensino, muitas das quaes já estão provadas como sendo optimas em outros paizes e mesmo no Brasil. 